\title{
Ying Chen, Querelle d'un squelette avec son double
}

\section{Simona Rossi}

\section{(2) OpenEdition}

\section{Journals}

\section{Edizione digitale}

URL: https://journals.openedition.org/studifrancesi/39913

DOI: 10.4000/studifrancesi.39913

ISSN: 2421-5856

\section{Editore}

Rosenberg \& Sellier

\section{Edizione cartacea}

Data di pubblicazione: 1 décembre 2004

Paginazione: 422

ISSN: 0039-2944

\section{Notizia bibliografica digitale}

Simona Rossi, «Ying Chen, Querelle d'un squelette avec son double», Studi Francesi [Online], 143 (XLVIII | II) | 2004, online dal 30 novembre 2015, consultato il 19 mai 2021. URL: http://

journals.openedition.org/studifrancesi/39913 ; DOI: https://doi.org/10.4000/studifrancesi.39913

Questo documento è stato generato automaticamente il 19 mai 2021.

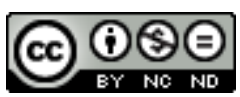

Studi Francesi è distribuita con Licenza Creative Commons Attribuzione - Non commerciale - Non opere derivate 4.0 Internazionale. 


\title{
Ying Chen, Querelle d'un squelette avec son double
}

\author{
Simona Rossi
}

\section{NOTIZIA}

YING CHEN, Querelle d'un squelette avec son double, Montréal, Les Éditions du Boréal, 2003, pp. 162.

1 Un romanzo ombra, uno scrigno polveroso pieno di sensazioni, d'immagini, di scene dai contorni indefiniti, quasi evanescenti: così si potrebbe definire l'ultima opera di Ying Chen, scrittrice quebecchese che dal suo primo romanzo, La Mémoire de l'eau (1996), sembra divertirsi a costruire magistralmente per il lettore una sorta di non-spazio, situato al di fuori di qualsiasi coordinata geografica e temporale.

2 E Querelle d'un squelette avec son double è immerso proprio in questa dimensione eterea, sospesa, dove perdersi è molto più facile che trovarsi, dove si teme talvolta di poter scomparire con il romanzo stesso, di veder evaporare lentamente la propria materialità, come accade alla protagonista senza nome, del resto, la femme de A., già al centro di un altro romanzo di Ying Chen, Le Champ dans la mer (2002), dove appare assalita dal tormento delle sue vite precedenti. Sì, perché questa donna, giovane e vecchia insieme, di fatto non esiste più, elle est un squelette, è resuscitata dalle ceneri e ha vissuto diverse esistenze, di cui pare ricordare fugaci e dolorosi frammenti. Da qui il tema del doppio, affrontato dall'autrice anche in Querelle d'un squelette, ma posto questa volta nel presente della protagonista.

3 È in questo modo che nel romanzo s'inseriscono due voci narranti: mentre la femme de A. si muove nel suo piccolo, banale universo, fatto di una casa inondata dagli odori della pasticceria di fronte, di un marito, di invitati che stanno per arrivare e di un dolce che deve essere pronto, dall'altra parte della rivière una donna è sepolta viva, agonizzante sotto le macerie della sua casa a causa di un violento sisma. Quest'ultima, essere ambiguo privo di passato, folle di dolore e di paura di morire, lancia un appello, una 
richiesta d'aiuto a quella che definisce sa scur, la sua unica parente, la sua gemella perduta, la sua anima e la sua creatrice, il suo doppio.

Alla femme de A., però, che combatte da tempo contro una grave malattia mentale, arriva solo una voce insistente, la quale diventa presto un'ossessione da fuggire e ignorare, come ha fuggito e ignorato, tempo addietro, quella donna che l'attendeva in strada e in pasticceria, di cui tutti avevano notato la somiglianza.

5 Ying Chen ci regala dunque due storie che si snodano simultanee, ma non solo: attraverso una prosa densa e compatta, unico appiglio per il lettore in un'atmosfera dalle tinte così sfumate, dove i personaggi cominciano dal nulla e finiscono nel nulla, l'autrice riesce anche a far comunicare spiritualmente queste due donne tramite una sorta di telepatia, facendole diventare nient'altro che voci nel cosmo chiassoso, echi che a loro modo si rispondono. Perché in fondo la femme de A. e la femme agonisante rappresentano due facce della medesima angoscia, della medesima ansia di vivere.

6 E in questo percorso di ricerca una dell'altra, di compenetrazione e di scambio di elementi, non si può evitare di farsi prendere dalla febbre della comprensione ad ogni costo, chiedendosi chi delle due mente, in preda al delirio, chi ha creato l'altra, chi è l'originale e chi la copia. A queste domande, purtroppo o per fortuna, il romanzo non da alcuna risposta.

7 Le ipotesi che si possono formulare sono diverse: potrebbe trattarsi davvero della storia di due sorelle gemelle, le cui capacità telepatiche sono leggenda collettiva, del resto, oppure si potrebbe vedere dietro all'insistenza sulla tematica del doppio la fobia moderna della clonazione umana, senza contare che le due voci potrebbero rappresentare anche il grido di dolore di quella parte di umanità che soffre a causa della diffusa indifferenza. Esse potrebbero addirittura ridursi ad una soltanto, ossia quella della femme de A., un essere in preda ad un profondo ed irrisolto conflitto interiore.

8 Ying Chen avrebbe potuto imporsi, certo, ma non l'ha fatto, probabilmente perché per lei, nemica degli schemi della ragione che si oppongono al sentire più autentico, il più grande regalo che si può fare ad un lettore è la libertà di cercare dentro di sé, in un percorso intimo e individuale, la propria risposta.

Un romanzo complicato ma toccante, dunque, che spinge a lasciare aperto lo scrigno della nostra sensibilità più profonda, al di là di qualsiasi barriera, spaziale o temporale, al di là dei limiti della nostra corporeità e del nostro essere mortali. 